\title{
PROGRAM BIMBINGAN KARIR PADA SISWA KELAS XII SMK ASSAABIQ SINGAPARNA
}

\author{
Feida Noorlaila Istiadah ${ }^{1}$, Aam Imaddudin ${ }^{2}$, Cucu Arumsari ${ }^{3}$, \\ Agung Nugraha $^{4}$, Dewang Sulistiana ${ }^{5}$, Gian Sugiana Sugara ${ }^{6}$ \\ ${ }^{123456}$ Universitas Muhammadiyah Tasikmalaya
}

Email: feida@umtas.ac.id'1 , aam.imaduddin@umtas.ac.id², cucu.arumsari@umtas.ac.id ${ }^{3}$, agung.nugraha@umtas.ac.id ${ }^{4}$, dewang.sulistiana@umtas.ac.id ${ }^{5}$, gian.sugiana@umtas.ac.id ${ }^{6}$

\begin{abstract}
ABSTRAK
Bimbingan Karir dimaksudkan untuk membantu siswa agar mengenal dan memahami dirinya, mengenal dunia kerja, merencanakan masa depan yang sesuai dengan bentuk kehidupan yang diharapkannya, mampu menentukan dan mengambil keputusan secara tepat dan bertanggung jawab atas keputusan yang diambilnya itu sehingga mampu mewujudkan dirinya secara bermakna (Supriatna, 2009: 12). Bimbingan karir ditujukan agar individu (siswa) mengalami proses learning to work, yakni belajar untuk bekerja. Artinya, proses pembelajaran yang dialami individu (siswa) saat ini dapat mendasari keputusan karier saat ini dan karir masa depan. Dalam Pengabdian pada masyarakat ini program studi Bimbingan dan Konseling mencoba menerapkan program bimbingan karir pada siswa kelas XII SMK Assaabiq Singaparrna tahun ajaran 2016/2017. Metode yang digunakan yaitu dengan diadakan seminar karir yang dilaksanakan khusus untuk kelas XII SMK Assaabiq Singaparna. Dalam pelaksanaan kegiatan, peserta terlihat antusias mengikuti kegiatan ditandai dengan banyaknya siswa memberikan pertanyaan pada sesi diskusi unstuk setiap sesi kegiatan. Selain itu juga diberikan motivasi dari salah satu alumni SMK Assaabiq yang telah sukses meniti karirnya dari mulai mendapatkan beasiswa kuliah sampai diterima menjadi PNS di Kemenhukam pada Tahun 2017. Keberlanjutan kegiatan ini yaitu dengan mengadakan sesi konseling kepada siswa yang ingin berkonsultasi terkait dengan perencanaan karir. Kegiatan konseling ini dilakukan secara insidental bagi yang membutuhkan layanan tersebut sebagai tindak lanjut dari kegiatan ini.
\end{abstract}

Kata kunci : Bimbingan, Bimbingan Karir, Siswa

\begin{abstract}
Career Guidance is intended to help students to know and understand themselves, to know the world of work, to plan for the future in accordance with the expected life form, able to determine and take decisions appropriately and responsible for the decisions that are taken so as to realize themselves meaningfully (Supriatna, 2009: 12). Career guidance is intended for individuals (students) to experience the process of learning to work, ie learning to work. That is, the learning process experienced by individuals (students) today can underlie current career decisions and future careers. In Community service this Guidance and Counseling study program try to apply career guidance program to class XII students of SMK Assaabiq Singaparrna academic year 2016/2017. The method used is a career seminar held specifically for class XII SMK Assaabiq Singaparna. In the implementation of the activity, the participants were enthusiastically participated in the activity marked by the number of students asking questions during the discussion session for each activity session. It was also given motivation from one of Assaabiq's vocational alumni who had successfully pursue his career from starting scholarship to university until accepted as civil servant in Kemenhukam in 2017 . The sustainability of this activity is by holding a counseling session to students who want to consult related to career planning. This counseling activity is conducted incidentally for those who need the service as a follow up of this activity.
\end{abstract}

Keywords: Guidance, Career Guidance, Student 


\section{PENDAHULUAN}

Dalam perkembangan karir, siswa SMK berada pada tahap ekplorasi. Adapun tugas perkembangan karir pada tahap ekplorasi diantaranya, mengenal keterampilan membuat keputusan karir dan memperoleh informasi yang relavan untuk membuat keputusan karir, menyadari minat dan kemampuan serta dapat menghubungkannya dengan kesempatan kerja, mengidentifikasi bidang dan pekerjaan yang cocok dengan minat dan kemampuan (Supriatna, 2009:23). Oleh karena itu perlu adanya upaya untuk membantu siswa dalam merencanakan karir masa depannya. Salah satunya yaitu dengan layanan bimbingan karir.

Mohamad Surya (Supriatna, 2009: 12) menyatakan bahwa bimbingan karier merupakan salah satu jenis bimbingan yang berusaha membantu individu untuk memecahkan masalah karier, memperoleh penyesuaian diri yang sebaik-baiknya antara kemampuan dan lingkungan hidupnya, memperoleh keberhasilan dan perwujudan diri dalam perjalanan hidupnya. Bimbingan karier adalah suatu proses bantuan, layanan, pendekatan terhadap individu agar dapat mengenal dan memahami dirinya, mengenal dunia kerja, merencanakan masa depan yang sesuai dengan bentuk kehidupan yang diharapkannya, mampu menentukan dan mengambil keputusan secara tepat dan bertanggung jawab atas keputusan yang diambilnya itu sehingga mampu mewujudkan dirinya secara bermakna (Supriatna, 2009: 12).

Pendidikan vokasi atau kejuruan adalah suatu pendidikan yang berbeda dengan pendidikan umum. Pendidikan kejuruan diarahkan untuk membentuk lulusan yang memiliki wawasan profesional, yaitu sesuatu yang tertanam di dalam diri seseorang yang mempengaruhi perilakunya, yaitu peduli kepada mutu (tidak asal jadi), bekerja cepat, tepat dan efisien tanpa atau dengan pengawasan orag lain, menghargai waktu, dan menjaga reputasi. Karakter seperti ini adalah karakter tenaga kerja yang disukai dan diperlukan oleh dunia kerja. Diperlukan suatu usaha pembentukan sikap profesional yang sistematis dan waktu yang lama di SMK untuk mencapai tujuan tersebut. Dibutuhkan juga perlakuan khusus (special treatment) bagi siswa tertentu, kelompok siswa tertentu, atau sekolah tertentu untuk membentuk keunggulan sesuai kondisi siswa, sekolah tempat belajarnya, dan potensi daerah tempat SMK berada (Supriadi, Dedi. 2002: 236).

SMK adalah salah satu sub-sistem dari sistem pendidikan nasional di Indonesia. SMK memainkan peranan strategis bagi penyediaan tenaga kerja terampil secara nasional. Dalam hubungan antara tujuan penyelenggaraan SMK dengan penyiapan karir siswanya, maka harus dipertimbangkan adanya konsep pendidikan karir yang terintegrasi didalamnya. Pendidikan karir (career education) di sekolah menengah atas (high school) mencakup pemberian kesempatan pada para siswa untuk mengeksplorasi lebih jauh dunia kerja, serta menarik hubungannya dengan minat, potensi dan kemampuan diri mereka.

Pendekatan bagi para siswa di jenjang ini bisa dibagi kedalam dua kelompok, yaitu: (1) para siswa yang berencana mencari pekerjaan segera setelah lulus sekolah menengah atas, serta (2) para siswa yang merencanakan untuk melanjutkan ke jenjang lebih tinggi. Pendekatan pendidikan karir bagi kedua kelompok ini harus berbeda namun tetap fleksibel, terutama bagi sekolah menengah yang khusus kejuruan. Terilhat jelas bahwa pendidikan karir di sekolah tidak bisa disamakan untuk seluruh siswa.

Menurut Sukardi (1989), tujuan pelaksanaan Bimbingan Karir di Sekolah adalah agar siswa dapat: (1) meningkatkan pengetahuannya tentang dirinya sendiri (self concept); (2) meningkatkan pengetahuannya tentang dunia kerja; (3) mengembangkan sikap dan nilai diri sendiri dalam menghadapi pilihan lapangan kerja dalam persiapan memasukinya; (4) meningkatkan ketrampilan berpikir agar mampu mengambil keputusan tenntang jabatan yang sesuai dengan dirinya dan tersedia dalam dunia kerja; dan (5) menguasai ketrampilan dasar yang penting dalam pekerjaan terutama kemampuan berkomunikasi, bekerja sama, berprakarsa dan lain sebagainya.

Kemudian lebih spesifik berkenaan dengan Sekolah Menengah Kejuruan (SMK) dalam Peraturan Pemerintah No. 29 Tahun 1990 tentang Pendidikan Menengah, disebutkan bahwa pendidikan menengah kejuruan mengutamakan penyiapan siswa untuk memasuki lapangan kerja 
serta mengembangkan sikap profesional. Karenanya BK karir haruslah dilaksanakan sesuai dengan kebutuhan di dunia kerja. Sasaran kompetensi yang ingin dicapai bagi lulusan SMK sudah cukup jelas, dan memiliki perbedaan dengan siswa SMA. Karenanya implikasi terhadap layanan BK karir yang diterima juga akan berbeda.

Tujuan yang ingin dicapai dalam pengabdian pada masyarakat ini yaitu dapat memberikan informasi, pemahaman, dan keterampilan pada siswa dalam perencanaan karir masa depannya dan juga diharapkan pada sekolah mitra dapat menerapkan program bimbingan karir khususnya untuk kelas XII SMK.

\section{BAHAN DAN METODE}

Dalam pelaksanaan pengabdian pada masyarakat ini dilaksanakan di SMK Assaabiq Singaparna yang beralamat di jalan Borolong No. 175 Cipakat Singaparna Tasikmalaya. Sasaran pada kegiatan ini yaitu kelas XII Tahun ajaran 2017/2018. Pelaksanaan kegiatan dilaksanakan pada tanggal 23-25 November 2017 bertempat di Aula SMK Assaabiq Singaparna.

\section{HASIL}

Kegiatan pertama dimulai pada hari Kamis tanggal 23 November 2017 materi pertama diisi oleh Feida Noorlaila Istiadah M.Pd dengan materi layanan mengenai "Perencanaan karir masa depan, motivasi berprestadi dalam meraih impian dan cita-cita". Peserta terlihat antusias dalam pelaksanaan kegiatan ini ditandai dengan banyaknya pertanyaan yang diajukan dari para peserta mengenai perencanaan karir masa depan. Tujuan dari pemberian layanan dengan materi tersebut yaitu diharapkan siswa mempunyai motivasi yang tinggi dalam merencanakan masa depannya mau dibawa kemana. Sehingga pada gilirannya siswa tersebut mampu untuk memahami keinginan, harapan dan impian dalam menentukan karir masa depannya. Selain itu kegiatan pada materi pertama ini juga diharapkan siswa mampu merumuskan dari hal yang paling kecil sampai dengan yang paling besar mengenai harapannya tersebut dalam sebuah peta impian. Dan pada akhirnya siswa mampu membedakan antara impian dan cita-cita.

Materi kedua dilaksanakan pada hari Sabtu tanggal 25 November 2017. Disampaikan oleh Aam Imaddudin M.Pd dengan judul materi yaitu "memaknai karir: memilih atau menunggu kesempatan". Tujuan dari pemberian layanan tersebut yaitu memberikan pemahaman kepada siswa bahwa karir tidak hanya masalah pekerjaan, tetapi maknanya karir adalah pilihan hidup sepanjang hayat. Selain itu kegiatan pada materi kedua ini juga diharapkan siswa pada akhirnya dapat menentukan karir nya dimasa depan yaitu dengan kesadaran dan juga kebermaknaan bahwa apapun yang akan dipilihnya nanti, itu merupakan salah satu ikhtiar dan siap menerima takdir baik dan buruk. Karena sejatinya karir adalah sebuah pilihan, diyakini, dijalankan, disyukuri.

Materi ketiga dilaksanakan pada hari Sabtu tanggal 25 November 2017. Disampaikan oleh Cucu Arumsari M.Pd dengan judul materi yaitu"memahami arah kecenderungan karir sesuai bakat dan minat". Tujuan dari pemberian layanan tersebut yaitu siswa dapat memiliki pemahaman mengenai potensi yang dia miliki. Karena bakat baru muncul atau teraktualisasi bila ada kesempatan untuk berkembang atau dikembangkan, sehingga mungkin saja terjadi seseorang tidak mengetahui dan tidak mengembangkan bakatnya. Sdangkan minat dapat menjadi indikator dari kekuatan seseorang diarea tertentu dimana ia akan termotivasi untuk mempelajarinya dan menunjukkan kinerja yang tinggi. Bakat akan 
sulit berkembang dengan baik apabila tidak diawali dengan adanya minat untuk hal tersebutatau yang berkaitan dengan bidang yang akan ditekuni. Oleh karena itu diharapkan siswa mampu menggali dan memahami potensi yang dimilikinya berkaitan dengan bakat dan minatnya sehingga pada akhirnya siswa mampu memutuskan karir masa depannya sesuai dengan bakat dan minatnya.

Keberlanjutan kegiatan ini yaitu dengan mengadakan sesi konseling kepada siswa yang ingin berkonsultasi terkait dengan perencanaan karir. Kegiatan konseling ini dilakukan secara insidental bagi yang membutuhkan layanan tersebut sebagai tindak lanjut dari kegiatan ini. Selain itu program BK karir ini juga direncanakan akan berkelanjutan tiap tahun ajaran kerjasama antara prodi Bimbingan dan Konseling dengan SMK Assaabiq.

\section{PEMBAHASAN}

Alasan yang melatarbelakangi diadakan kegaiatn pengandian pada masayarakat berupa program bimbingan karir untuk kelas XII di SMK yaitu karena secara khusus tujuan bimbingan karir di SMK adalah untuk membantu atau memfasilitasi perkembangan individu agar memiliki kemampuan dalam memahami dan menilai dirinya terutama potensi dasar (bakat, minat, cita-cita, kecakapan, dan sikap) yang terkait dengan dunia kerja atau studi lanjutan yang akan dimasukinya kelak. Oleh karena itu maka setiap siswa perlu dibantu untuk memahami dan menilai potensi dasar yang dimilikinya sehingga dapat menentukan pilihan atau mengambil keputusan yang sesuai dengan pilihannya (Supriatna, 2009: 4).

Selain itu diharapkan siswa dapat mengetahui lingkungan pekerjaan/studi lanjutan yang berhubungan dengan potensi dirinya serta memahami jenis pendidikan atau pelatihan yang diperlukan untuk mengembangkan karir dalam bidang tertentu. Dan diharapkan siswa dapat merencakan masa depan, yaitu merancang kehidupan secara rasional untuk memperoleh peranperan yang sesuai dengan minat, kemampuan dan kondisi kehidupan sosial-ekonomi (Supriatna, 2009:5).

Syamsu Yusuf (Juwitaningrum, 2013: 1134) menyebutkan perkembangan berpikir pada remaja antara lain " dapat memikirkan masa depan dengan membuat perencanaan dan mengeksplorasi berbagai kemungkinan untuk mencapainya". Maka berdasar pendapat ini, remaja mau tidak mau hams menyadari bahwa dia harus segera memilih dan mempersiapkan karir yang tepat dengan potensi dan kondisinya. Pada kenyataannya, masih banyak ditemukan siswa yang bare sadar memilih dan merencanakan kerja pada saat masa-masa kritis (terlalu terlambat melakukan pilihan dan persiapan). Subrata (Juwitaningrum, 2013:135) melakukan survey persiapan karir sejumlah siswa SMA di Surabaya menunjukkan $85 \%$ siswa ragu terhadap karir masa depannya, $80 \%$ belum menetapkan karir masa depannya dengan mantap, $75 \%$ mengalami kesulitan dalam memutuskan dan merencanakan karir dengan baik. Walaupun begitu $90 \%$ menyadari pemilihan karir merupakan proses yang penting yang dengannya seseorang bisa mempersiapkan diri dengan melakukan pilihan-pilihan pendidikan maupun latihan.

Layanan atau program Bimbingan karir di Indonesia seharusnya memahami dan memenuhi kebutuhan-kebutuhan siswa dalam perkembangan karir sehingga memeiliki ketrampilan karir pada saat meninggalkan bangku sekolah. Hoyt (Juwitaningrum, 2013: 135) mengemukakan ada empat kebutuhan utama yaitu kebutuhaan untuk:

a. Merencanakan pendidikan pasca sekolah menengah yang berorientasi karir.

b. Memperoleh ketrampilan umum dalam cakap kerja, adaptasi kerja, dan peningkatan kerja sehingga mampu mengikuti perubahan dunia kerja setelah dewasa.

c. Penekanan pentingnya nilai-nilai kerja,

d. Merencanakan cara-cara menyibukkan diri dalam pekerjaan sebagai bagian dari keseluruhan perkembangan karir.

\section{KESIMPULAN DAN SARAN}


Kesimpulan yang dapat diambil pada pengabdian pada masyarakat ini bahwasanya program layanan Bimbingan Karir sangat diperlukan khususnya untuk meningkatkan kematangan karir bagi siswa. Dari keseluruhan pelaksanaan bimbingan karir, siswa akan memperoleh berbagai informasi mengenai karir, tumbuhnya sikap menghargai pekerjaan yang diamati, mendapatkan gambaran yang objektif tentang dirinya sendiri, dan memahami dirinya dalam kaitannya dengan dunia kerja, pendidikan, sosial, dan masalah-masalah kemasyarakatan lainnya. Adapun saran Bagi guru BK sesuai dengan hasil pengabdian secara keseluruhan agar konselor atau guru BK dapat meningkatkan layanan konseling individual sesuai dengan kebutuhan siswa seperti pilihan dan latihan keterampilan khusus, informasi pekerjaan dan dunia kerja, dan pilihan perguruan tinggi sesuai dengan arah pengembangan karir.

\section{UCAPAN TERIMA KASIH}

Ucapan terima kasih kepada 1) Rektor Universitas Muhammadiyah Tasikmalaya beserta jajarannya, 2) Dekan Fakultas Keguruan dan Ilmu Pendidikan Universitas Muhammadiyah Tasikmalaya beserta jajarannya, 3) Ketua LPPM Universitas Muhammadiyah Tasikmalaya 4) Dosen dan Mahasiswa Bimbingan dan Konseling Universitas Muhammadiyah Tasikmalaya, 5) Sekolah Mitra yaitu SMK Assaabiq, 6) Siswa-siswi kelas XII SMK Assaabiq.

\section{DAFTAR PUSTAKA}

Juwitaningrum, Ita. 2013. "Program Bimbingan Karir untuk Meningkatkan Kematanga Karir Siswa SMK". Yogyakarta: Psikopedagogia Jurnal Bimbingan dan Konseling Universitas Ahmad Dahlan. Volume 2. No.2: 132-147.

Sukardi, Dewa Ketut. 1989. Bimbingan Karir di Sekolah-Sekolah. Jakarta: Ghalia Indonesia

Supriadi, Dedi. 2002. Sejarah Pendidikan Teknik dan Kejuruan di Indonesia, Membangun Manusia Produktif. Departemen Pendidikan Nasional, Direktorat Jenderal Pendidikan Dasar dan Menengah: Direktorat Pendidikan Menengah Kejuruan.

Supriatna, Mamat. 2009. Bimbingan Karir di SMK. Bandung: Upi 


\section{LAMPIRAN}

Tabel 1. Inventori Kematangan Karir

Beri tanda Ceklis (V) pada Ya atau Tidak atas pernyataan berikut ini!

\begin{tabular}{|c|c|c|c|}
\hline \multirow[t]{2}{*}{ No. } & \multirow[t]{2}{*}{ Pernyataan } & \multicolumn{2}{|c|}{ Pilihan Jawaban } \\
\hline & & Ya & Tidak \\
\hline 1 & Saya memilih sekolah disini berdasarkan keputusan orang tua (-) & & \\
\hline 2 & Saya sadar bahwa masa depan perlu dipersiapkan $(+)$ & & \\
\hline 3 & $\begin{array}{l}\text { Saya bertanya kepada seseorang yang dianggap berhasil dalam hidup } \\
\text { tentang cara mengambil keputusan }(+)\end{array}$ & & \\
\hline 4 & $\begin{array}{l}\text { Saya menjadikan pengetahuan tentang pekerjaan sebagai dasar } \\
\text { pertimbangan dalam menentukan aktivitas yang berkaitan dengan } \\
\text { cita-cita masa depan }(+)\end{array}$ & & \\
\hline 5 & Saya bingung dengan karir masa depan saya (-) & & \\
\hline 6 & $\begin{array}{l}\text { Saya berupaya mengetahui cara memahami minat orang yang } \\
\text { berhasil dalam karirnya }(+)\end{array}$ & & \\
\hline 7 & $\begin{array}{l}\text { Saya berupaya memperkaya pengetahuan tentang pekerjaan yang ada } \\
(+)\end{array}$ & & \\
\hline 8 & $\begin{array}{l}\text { Saya mengetahui persyaratan memasuki bidang pekerjaan yang } \\
\text { diminati }(+)\end{array}$ & & \\
\hline 9 & $\begin{array}{l}\text { Saya meyakinkan bidang karier saya dengan mencari informasi } \\
\text { tentang } \\
\text { kesesuaian antara diri dengan karier masa depan yang diminati }(+)\end{array}$ & & \\
\hline 10 & Saya belum mengetahui tugas dari pekerjaan yang saya minati (-) & & \\
\hline 11 & $\begin{array}{l}\text { Saya memahami peralatan/instrumen dari pekerjaan yang saya minati } \\
(+)\end{array}$ & & \\
\hline 12 & $\begin{array}{l}\text { Saya mendiskusikan rencana karier dengan orang yang dituakan } \\
\text { (konselor, guru, orang tua, kakak, ustad, dll) }(+)\end{array}$ & & \\
\hline 13 & $\begin{array}{l}\text { Saya mengikuti kursus sesuai dengan bidang karier yang diinginkan } \\
(+)\end{array}$ & & \\
\hline 14 & $\begin{array}{l}\text { Saya bekerja sambilan (part time) sesuai dengan bidang karier yang } \\
\text { diinginkan }(+)\end{array}$ & & \\
\hline 15 & $\begin{array}{l}\text { Saya ingin memanfaatkan orang yang dituakan (guru, konselor, orang } \\
\text { tua, kakak, ustad, dll) sebagai sumber informasi karier }(+)\end{array}$ & & \\
\hline 16 & $\begin{array}{l}\text { Saya memilih bidang karier yang sesuai dengan kelebihan dan } \\
\text { keunggulan diri }(+)\end{array}$ & & \\
\hline 17 & $\begin{array}{l}\text { Saya berpendapat bahwa karier masa depan sudah direncanakan oleh } \\
\text { Tuhan, karena itu manusia tidak perlu merencanakan }(-)\end{array}$ & & \\
\hline 18 & Saya siap atas risiko dari keputusan memilih sekolah di sini (+) & & \\
\hline 19 & $\begin{array}{l}\text { Saya sudah mulai mengidentifikasi peluang-peluang karier yang ada } \\
(+)\end{array}$ & & \\
\hline 20 & Saya terdorong untuk mampu menciptakan peluang kerja $(+)$ & & \\
\hline
\end{tabular}

Catatan :

1. Bagi pernyataan positif, jawaban YA diberi skor 1 dan TIDAK diberi skor 0 , sedangkan bagi pernyataan negatif jawaban YA diberi skor 0 dan jawaban

TIDAK diberi skor 1.

2. Skor Total adalah 20

3. Siswa yang skornya di atas 16 cenderung memiliki kesiapan untuk mengambil keputusan karier dan yang skornya 16 ke bawah cenderung kurang atau tidak 
memiliki kesiapan untuk mengambil keputusan karier

Tabel 2.

\section{SUSUNAN ACARA}

Kegiatan : Program BK Karir pada Siswa Kelas XII SMK Assaabiq Singaparna

Tema $\quad$ : Meraih mimpi, Menggapai Prestasi dan Menata Masa Depan

Hari/ Tanggal : Sabtu, 25 November 2017

Tempat : : Aula SMK Assaabiq

\begin{tabular}{|c|c|c|c|}
\hline Waktu & Acara & Pembicara & keterangan \\
\hline $08.00-08.10$ & Pembukaan & $\mathrm{MC}$ & \\
\hline $08.10-08.20$ & Pembacaan Ayat Suci Alquran & Miftah Al-Mubarok & $\begin{array}{l}\text { Mahasiswa } \\
\text { Prodi BK } \\
\text { Angkatan } 2016\end{array}$ \\
\hline \multirow[t]{3}{*}{$08.20-08.40$} & Sambutan -sambutan & & \\
\hline & $\begin{array}{l}\text { 1. Sambutan dari ketua prodi } \\
\text { Bimbingan Konseling } \\
\text { Universitas Muhammadiyah } \\
\text { Tasikmalaya }\end{array}$ & $\begin{array}{l}\text { Aam Imaddudin } \\
\text { M.Pd }\end{array}$ & $\begin{array}{l}\text { Ketua Prodi BK } \\
\text { Umtas }\end{array}$ \\
\hline & $\begin{array}{l}\text { 2. Sambutan dari Kepala } \\
\text { Sekolah SMK Assaabiq } \\
\text { Singaparna }\end{array}$ & $\begin{array}{l}\text { Drs. H. Dadang } \\
\text { Syarif Hidayat M.Pd }\end{array}$ & $\begin{array}{l}\text { Kepala } \\
\text { Sekolah SMK } \\
\text { Assaabiq } \\
\text { Singaparna }\end{array}$ \\
\hline $08.40-08.50$ & Pemberian cendramata & & $\begin{array}{l}\text { Cendramata } \\
\text { diberikan oleh } \\
\text { ketua prodi BK } \\
\text { kepada kepala } \\
\text { sekolah SMK } \\
\text { Assaabiq }\end{array}$ \\
\hline $08.50-09.00$ & Doa dan Penutup & Miftah Al-Mubarok & $\begin{array}{l}\text { Mahasiswa } \\
\text { Prodi BK } \\
\text { angkatan } 2016\end{array}$ \\
\hline $09.00-09.10$ & Break (persiapan) & & \\
\hline $09.10-09.50$ & Materi 1 & \multirow{2}{*}{$\begin{array}{l}\text { Aam Imaddudin } \\
\text { M.Pd }\end{array}$} & \multirow{2}{*}{$\begin{array}{l}\text { Ketua Prodi } \\
\text { Bimbingan dan } \\
\text { Konseling }\end{array}$} \\
\hline $09.50-10.00$ & Tanya jawab & & \\
\hline $10.00-10.40$ & Materi 2 & \multirow{2}{*}{$\begin{array}{l}\text { Cucu Arumsari } \\
\text { M.Pd }\end{array}$} & \multirow{2}{*}{$\begin{array}{l}\text { Dosen Prodi } \\
\text { BK Umtas }\end{array}$} \\
\hline $10.00-10.50$ & Tanya Jawab & & \\
\hline $10.50-11.20$ & Materi 3 & \multirow{2}{*}{$\begin{array}{l}\text { Taufik Nugraha } \\
\text { S.Hum }\end{array}$} & \multirow{2}{*}{$\begin{array}{l}\text { Alumni SMK } \\
\text { Assaabiq } \\
\text { Tahun Lulus }\end{array}$} \\
\hline $11.20-11.30$ & Tanya jawab & & \\
\hline
\end{tabular}


Feida Noorlaila Istiadah ${ }^{1}$, Aam Imaddudin ${ }^{2}$, Cucu Arumsari ${ }^{3}$, Agung Nugraha ${ }^{4}$, Dewang Sulistiana ${ }^{5}$, Gian Sugiana Sugara ${ }^{6}$

\begin{tabular}{|l|l|l|l|}
\hline & & & $\begin{array}{l}\text { 2013, } \\
\text { penerima } \\
\text { beasiswa bidik } \\
\text { misi dan lulus } \\
\text { tes CPNS 2017 }\end{array}$ \\
\hline $11.30-11.40$ & Penutup & MC & \\
\hline $11.40-12.00$ & Ramah Tamah & & \\
\hline
\end{tabular}

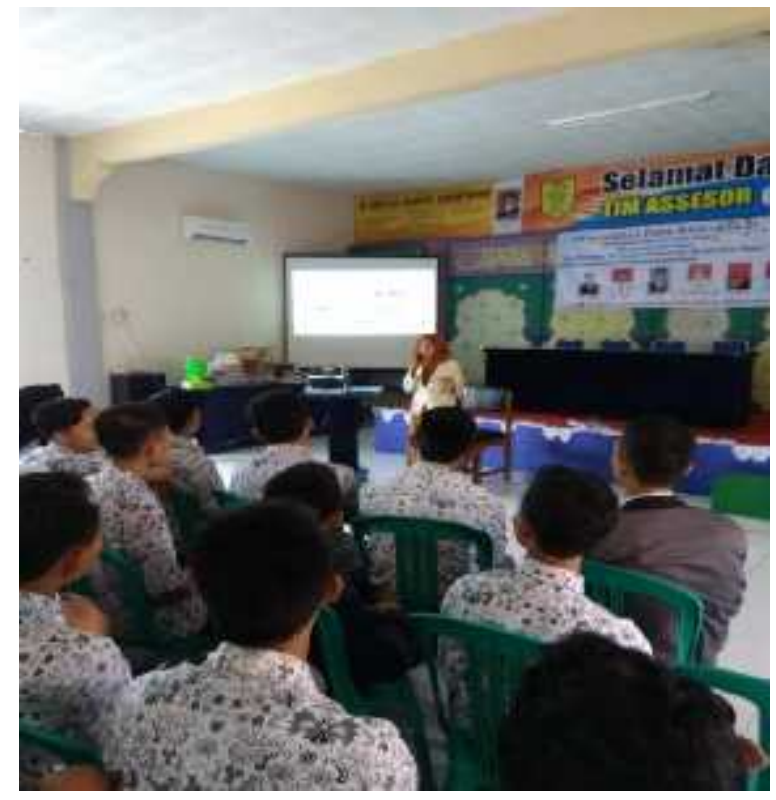

Gambar 1. Materi ke-1 oleh Feida Noorlaila

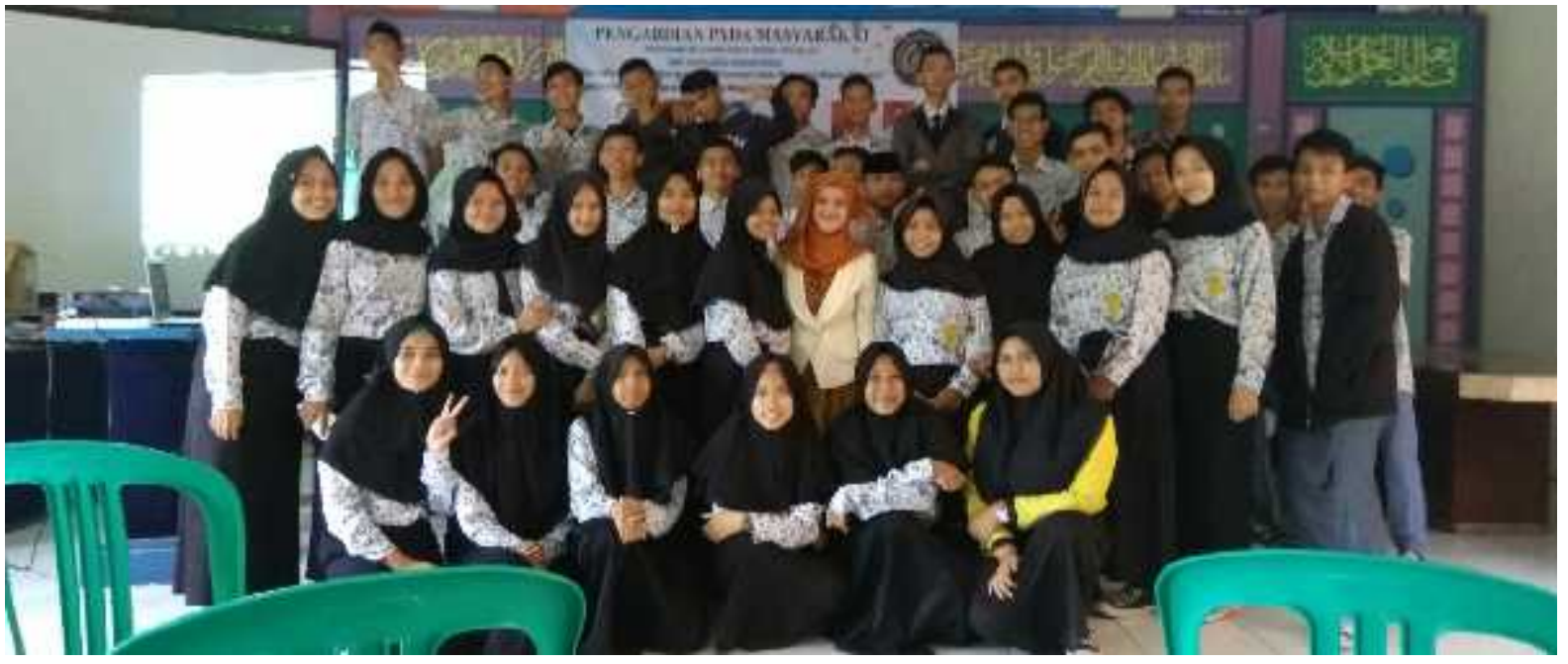

Gambar 2. Foto bersama dengan sebagian peserta kegiatan 


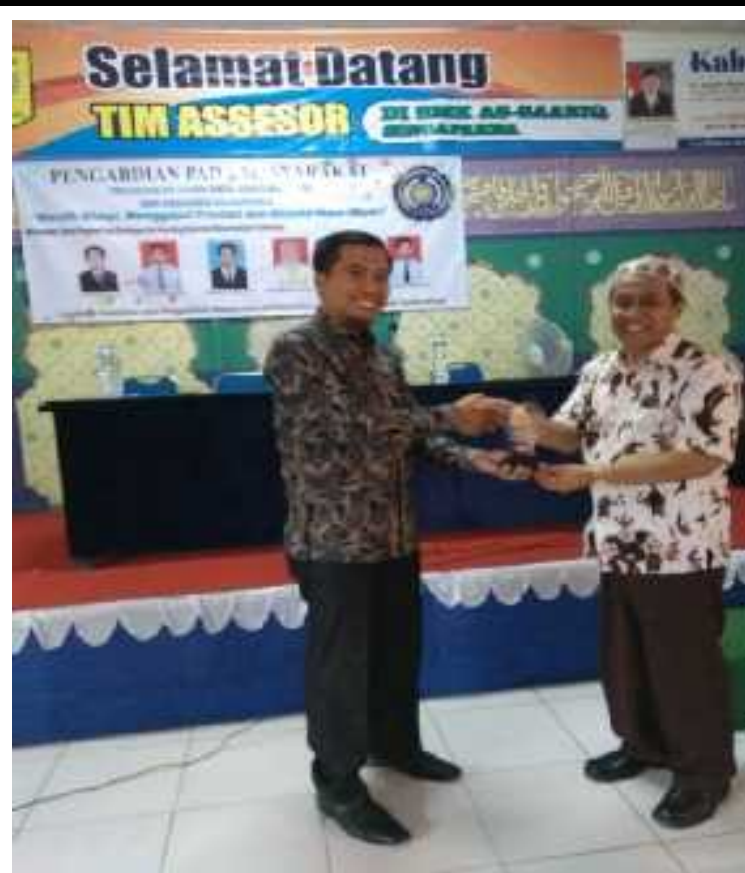

Gambar 3. Pemberian Cendramata oleh Ketua Prodi Bk kepada Kepala Sekolah SMK Assaabiq

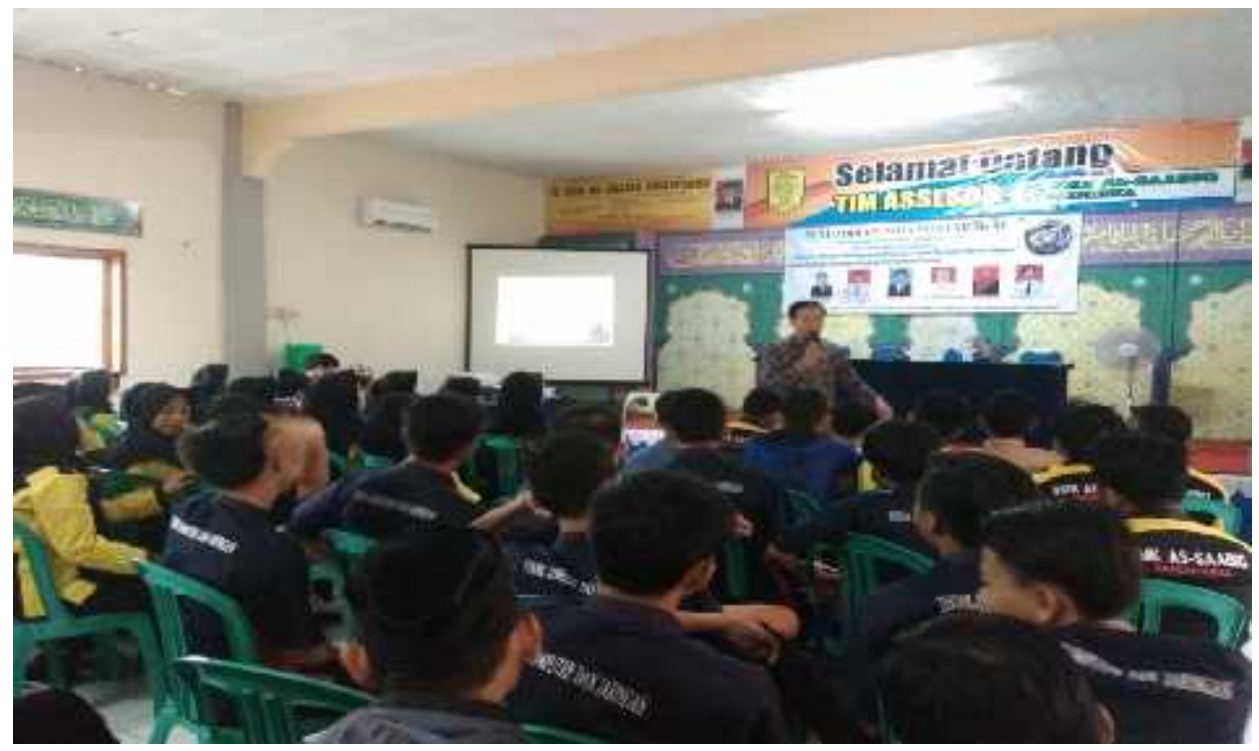

Gambar 4. Materi ke-2 oleh Aam Imaddudin M.Pd 
Feida Noorlaila Istiadah ${ }^{1}$, Aam Imaddudin ${ }^{2}$, Cucu Arumsari ${ }^{3}$,

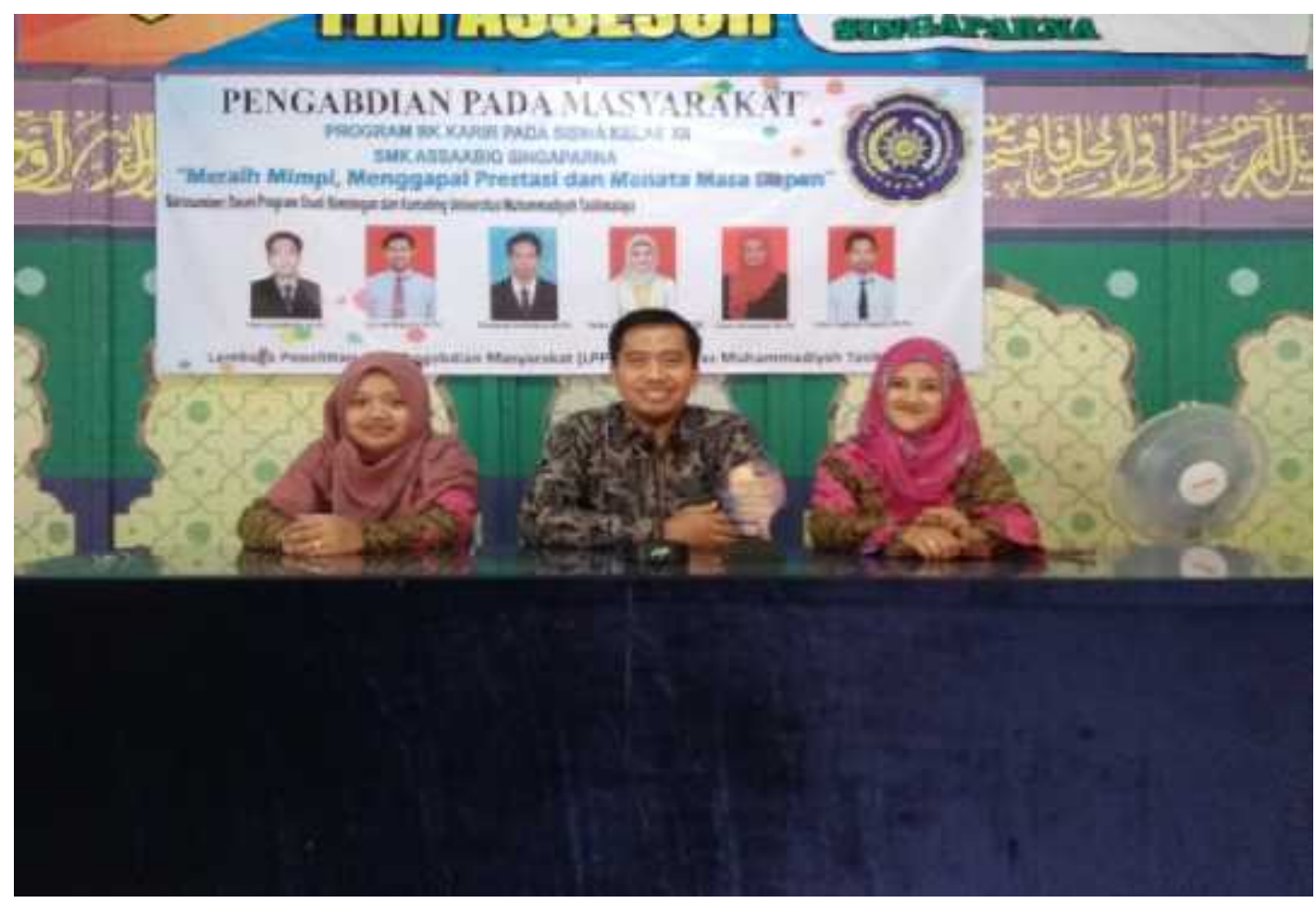

Gambar 5. Narasumber Kegiatan Pengabdian pada Masyarakat

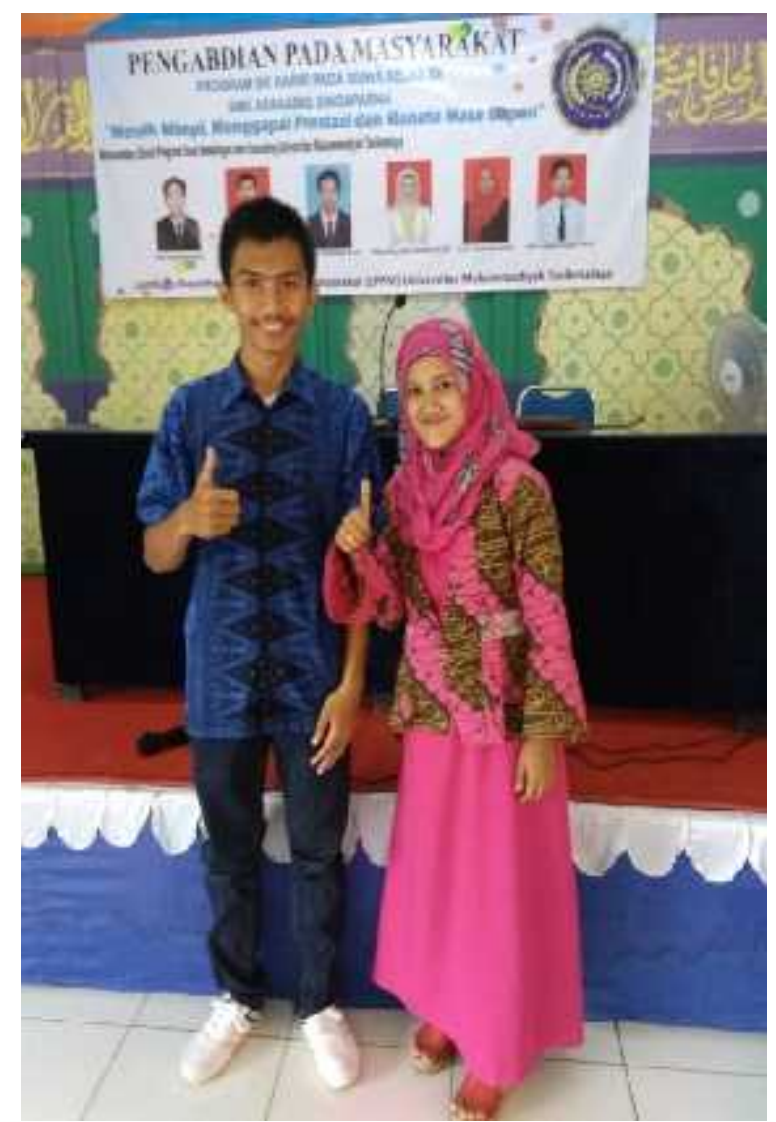

Gambar 6. Alumni SMK Assaabiq yang telah sukses menggapai cita-cita dan impian 